\title{
UM MODELO DE AVALIAÇÃO DE APRENDIZAGEM DA DISCIPLINA DE HISTÓRIA BASEADO EM PROJETOS E MAPAS CONCEITUAIS ${ }^{1}$
}

\author{
A MODEL OF LEARNING ASSESSMENT, OF THE HISTORY DISCIPLINE, BASED ON \\ CONCEPTUAL PROJECTS AND MAPS
}

Fábio Paraguaçu Duarte da Costa²

Patricia Maria dos Santos ${ }^{3}$

\begin{abstract}
RESUMO. Este trabalho buscou investigar o estudo da disciplina de História como Ciência, através da técnica de criação de Mapas Conceituais e da abordagem de Aprendizagem Baseada em Projetos (Project-Based Learning). Logo, a proposta do referido trabalho é analisar se houve crescimento cognitivo através de uma avaliação do uso da abordagem de Aprendizagem Baseada em Projetos no conteúdo de História. Os sujeitos da pesquisa foram 40 alunos de uma turma do 90 Ano da Escola Estadual Professor José da Silveira Camerino, em 2016. A metodologia utilizada foi a pesquisa qualitativa. Aplicamos as duas técnicas mencionadas e avaliamos que houve o desenvolvimento da aprendizagem, bem como o crescimento cognitivo dos alunos através da criação de projetos e da modelagem do conhecimento adquirido nos mapas conceituais. O resultado foi obtido através de um Modelo Avaliativo de Aprendizagem Cognitiva do ensino de História.
\end{abstract}

Palavras - chaves: Modelo. Projetos. Mapas conceituais. Aprendizagem. História.

\section{ABSTRACT:}

This work sought to investigate the study of the discipline of History as Science, through the technique of creating Conceptual Maps and the approach of Project Based Learning (ProjectBased Learning). Therefore, the purpose of this work is to analyze whether there has been cognitive growth through an evaluation of the use of the Project Based Learning approach in the History content. The research subjects were 40 students from a 9th grade class at the Professor José da Silveira Camerino State School, in 2016. The methodology used was qualitative research. We applied the two mentioned techniques and evaluated that there was the development of learning, as well as the cognitive growth of the students through the creation of projects and the modeling of the knowledge acquired in the concept maps. The result was obtained through an Evaluation Model of Cognitive Learning in the teaching of History.

Keywords: Model. Projects. Conceptual maps. Learning. History.

\footnotetext{
${ }^{1}$ Pesquisa realizada, para obtenção de dados para o desenvolvimento da dissertação do Mestrado da Pós-Graduação em Modelagem Computacional do Conhecimento em Educação, com o financiamento de bolsa da CAPES.

2 Professor Doutor do Programa de Pós-Graduação em Modelagem Computacional do Conhecimento em Educação. Instituto de Computação- IC /Universidade Federal de Alagoas UFAL.

3 Mestre em Educação pelo Programa de Pós-Graduação em Modelagem Computacional do Conhecimento Em Educação. Instituto de Computação - IC/Universidade Federal de Alagoas UFAL.
} 


\section{Introdução}

Mapas Conceituais, segundo Cury, Gava e Menezes (2002) são ferramentas utilizadas para modelar e representar conhecimentos adquiridos ao longo do processo de aprendizagem, por meio da descrição de conceitos que mantêm relação de significados entre si. E uma das particularidades dos Mapas Conceituais é de proporcionar a quem o está construindo várias dimensões e características próprias de acordo com o perfil do criador.

A sua estrutura é baseada na organização hierárquica das informações, partindo inicialmente daquelas mais importantes, os conceitos, e por àquelas menos inclusivas, os termos, ocupando uma posição hierárquica inferior em relação aos conceitos. E devido à experiência e conhecimento de cada aluno a tendência é de que cada mapa seja diferente, além de também contar para isso com as diferentes interpretações feitas por cada um deles sobre o tema que deu origem ao referido mapa, de forma a permitir a análise individual do aprendizado deles.

Como ferramenta avaliativa, o mapa não pode ser classificado de acordo com a construção do aluno, sendo certo ou errado, pois a sua estrutura dependerá da forma que foi criado, porém o que precisa ser avaliado como certo ou errado é o que o aluno aprendeu sobre o conteúdo estruturado. O processo de aprendizagem através do mapeamento conceitual foi desenvolvido por Joseph Novak na Universidade de Cornell, baseado na teoria de David Ausubel fundamentada na aprendizagem significativa em que o aprendizado do aluno inicia-se pelo que ele já conhece, os subsunçores, e depois acrescenta a estes novos conceitos (CAMARGO; PADILHA; POLACHINI, 2013).

Os mapas podem ainda oferecer aos alunos o uso correto e rápido do material analisado, através da separação e inclusão daquilo que de fato é significativo para o aprendizado, de forma a descartar tudo aquilo que é supérfluo ao estudo. Já a Aprendizagem Baseada em Projetos (Project-Based Learning) se caracteriza pelo desenvolvimento e construção do conhecimento do aprendiz através da aplicação de problemas sociais, econômicas e culturais com 
objetivo do aluno criar e/ou encontrar soluções para resolvê-los (HINTERHOLZ; SANTOS, 2017).

Esse desenvolvimento, se dá com maior eficácia ao passo que ele estiver pesquisando, debatendo e colocando seus conhecimentos em prática, como propõe a Aprendizagem Baseada em Projetos, já que ela utiliza problemas reais ou criados pelo aprendiz para servir de ferramenta avaliativa, para o professor, do conhecimento desses aprendizes ao passo em que eles conseguem solucionálos.

O aluno, de acordo com a teoria construtivista, é o personagem central do processo de ensino e aprendizagem direcionando assim estas fases para auxiliálo na construção do seu conhecimento, através de mecanismos que o façam buscar possibilidades para resolver problemas com eficiência ao utilizar sua cognição para traçar etapas e executá-las no intuito de solucioná-los, segundo Guerra e Vasconcelos (2009).

$\mathrm{Na}$ realização da Aprendizagem Baseada em Projetos, segundo Klein (2013), o professor apresenta aos alunos, que deverão ser divididos em pequenos grupos, os problemas reais para que eles encontrem, de forma cooperativa e colaborativa, soluções ou alternativas para sanar ou amenizar determinado problema. Para a introdução dessa abordagem é necessário recorrer aos pilares da aprendizagem significativa que é o processo de utilização de conhecimentos prévios sobre o conteúdo que o indivíduo possui e que somado a outras informações, sejam produzidos novos conhecimentos, através da elaboração de novas ideias.

O uso desses conhecimentos prévios, pelo aluno investigador, adicionados a novas informações que adquiriu durante o estudo, ajudou a formular questões críticas e provocativas que estimularam os outros integrantes do grupo. Ativar esses conhecimentos prévios em cada membro do grupo proporcionou novas intervenções na construção de conhecimentos, de forma a estimular a aprendizagem significativa.

Logo, o uso da Aprendizagem Baseada em Projetos, de acordo com as experiências dos estudiosos acima mencionados, proporciona aos aprendizes uma possibilidade de avançar no aprendizado através de uma abordagem construtivista onde eles serão os personagens principais e ativos desse processo 
de aprendizagem, cooperando e colaborando no desenvolvimento de projetos e compartilhando entre seus pares as descobertas realizadas de forma a promover uma interação entre eles e, consequentemente, a construção do conhecimento por cada um.

O professor nessa abordagem assume uma postura de orientador, facilitador da construção de conhecimento dos aprendizes, onde não mais transmite informações sobre determinado conteúdo, mas sim estimula e orienta os aprendizes através de problemas relacionado a esse conteúdo, de forma a torná-los autônomos em suas escolhas, nas etapas de cada processo da resolução do problema, onde eles desenvolvem trabalhos apoiados na Aprendizagem Baseada em Projetos durante as aulas.

A História, segundo Oliveira (2015), deve ser tratada como um problema a ser solucionado, onde o professor instiga o aprendiz a investigar os pontos que relacionam cada informação sobre determinado fato e com isso encontrar as possíveis soluções ou explicações ao questionamento feito. É tratá-la como uma ciência que pode ser questionável, onde os aprendizes podem ter compreensões diferentes e, através de suas investigações, sustentar suas teses sobre o problema investigado.

O modelo proposto que tem como um dos objetivos de melhorar o ensino e aprendizagem dos alunos, foi aplicado e verificou-se, através da concepção e realização de uma sequência ordenada de etapas, a evolução cognitiva do aprendiz. Compreender os fatores que levaram a ocorrência de determinado fato histórico e suas consequências sempre foi um problema para os aprendizes. Nesse sentido, a História como disciplina que investiga o passado e o presente da humanidade pode ser ensinada como um processo de investigação de forma similar a aprendizagem das ciências exatas.

Além disso, para a aprendizagem de conceitos históricos, segundo Carretero (1997) deverá ser mantida uma linha de pensamento com o evento do passado, suas consequências futuras e contextualizá-lo aos fatos ocorridos no presente que evidentemente possuirá relações. Ela deve ser tratada como um problema a ser solucionado, onde o professor encoraja o aluno a investigar os pontos que relacionam cada informação sobre determinado fato e com isso encontrar a (s) possível (eis) solução ao questionamento feito. 
É tratar a História como uma ciência que pode ser questionável, onde os alunos podem ter compreensões diferentes e através de suas investigações sustentar suas teses. Logo, partimos do pressuposto de que utilizar metodologias construtivistas, de acordo com Klein (2013) auxilia o aluno a compreender como se deu os acontecimentos históricos, assim como utilizar a Aprendizagem Baseada em Projetos para encontrar soluções para sanar os problemas, bem como o uso dos mapas para demonstrar esse aprendizado a partir da representação do conhecimento adquirido através da utilização de conceitos e termos.

A referida disciplina possui grande importância no currículo escolar, que vem contando com o auxílio de novas abordagens e recursos tecnológicos que foram introduzidos para possibilitar um maior desenvolvimento cognitivo dos aprendizes Kantovitz (2012).

Nessa direção, esse artigo se propõe a investigar o impacto do uso da abordagem da Aprendizagem Baseada em Projetos bem como da técnica de construção de Mapas Conceituais na aprendizagem de História, através da realização de estudos, visando avaliar a evolução do conhecimento analisado através da elaboração destes mapas pelos aprendizes tornando-os questionadores da história.

Assim, por meio dessa técnica será possível medir o desenvolvimento da aprendizagem da disciplina, onde a professora responsável pela pesquisa avaliará o aluno durante as seguintes etapas: (a) leitura do conteúdo abordado em sala de aula; (b) produção dos projetos; (c) construção dos mapas conceituais; (d) avaliação do que o aluno criou, desde o agrupamento dos conceitos mais relevantes e seus termos, até a exposição destes no mapa; (e) e avaliação de como se deu o desenvolvimento individual dos alunos, de forma a agregar o conhecimento visto em sala de aula com o adquirido durante as investigações.

Logo, esperamos que a introdução dos Mapas Conceituais e da Aprendizagem Baseada em Projetos, no processo de aprendizagem, possibilite aos alunos tornarem-se mestres de seu conhecimento. Além disso, esperamos também que o mapeamento da construção do conhecimento do aluno, permita ao professor verificar a evolução do seu desenvolvimento cognitivo, suas 
dificuldades em correlacionar ideias, dificuldades em elaborar novos questionamentos e a possibilidade de trabalhar em equipe.

E nesse sentido, cabe ao professor orientar o aluno a utilizar seus conhecimentos prévios em benefício próprio e de sua equipe no desenvolvimento dos projetos e no mapeamento da construção do conhecimento, que neste trabalho foi utilizado como ferramenta avaliativa do aprendizado dos alunos.

\section{Material e métodos}

O estudo foi desenvolvido através da metodologia de pesquisa qualitativa, onde foi aplicado o modelo avaliativo de aprendizagem cognitiva de História, amparadas por bibliografias que tratam do tema proposto. Os sujeitos do estudo foram 40 alunos, de ambos os sexos, da turma do 90 Ano do turno matutino da Escola Estadual Professor José da Silveira Camerino, em 2016. A referida escola fica situada no Centro Educacional de Pesquisa Aplicada - CEPA, frequentadas por alunos oriundos de bairros periféricos da cidade de Maceió - Alagoas.

Também foi utilizado a metodologia de avaliação formativa que tem como objetivo informar tanto o professor como ao aprendiz, como está sendo desenvolvida a aprendizagem durante todo o processo de ensino Rabelo (2009, p. 70). Dessa forma, a pesquisa foi construída através de quatro etapas: estudo dos conteúdos de história, desenvolvimento dos projetos, construção dos mapas conceituais (manualmente e posteriormente utilizando a ferramenta Cmap Tools) e avaliação da representação do conhecimento nos mapas.

A análise de dados foi realizada através do levantamento das informações sobre os avanços obtidos no aprendizado com o uso da Abordagem Baseada em Projetos e com a introdução da modelagem dos mapas conceituais sobre alguns problemas, como por exemplo, Como poderia ser evitada a quebra da Bolsa de Nova York?. Assim, iniciamos o trabalho com aulas expositivas, com os alunos, sobre conteúdos de História, com momentos de discussões e apontamentos de dúvidas, onde identificamos os conhecimentos prévios dos alunos sobre o conteúdo.

Também foi discutido com os alunos como se dava o desenvolvimento dos projetos (Project-Based Learning) e a elaboração dos mapas conceituais, que foi 
a principal forma de avaliação no processo de ensino. A segunda etapa do trabalho consistiu na elaboração dos projetos pelos alunos, seguindo algumas fases do processo da Aprendizagem Baseada em Projetos, segundo Castanheira et al. (2012), tais como:

- Definição do grupo (ex: estabelecer a quantidade adequada de membros);

- Desenvolvimento das etapas do projeto (Ex: Escolha do tema, realizar pesquisas e leituras em livros e na Web, desenvolver trabalho físico);

- Seleção dos conhecimentos mais importantes adquiridos em pesquisa sobre o assunto que serviu para solucionar o problema (Ex: Conteúdos chave);

- Interação entre os membros do grupo (Ex: Explanação da solução encontrada, troca de saberes adquiridos com as pesquisas sobre o tema);

- Elaboração do Mapa Conceitual.

Após a elaboração dos mapas pelos alunos, que consiste na terceira etapa do estudo, eles foram analisados pela professora para escolher o que atendia aos critérios estruturais de um mapa, bem como demonstrar o conhecimento prévio de cada aluno sobre o problema escolhido e a forma como cada conceito foi utilizado na conexão deste conhecimento.

Logo, o resultado esperado era que a introdução da Aprendizagem Baseada em Projetos e da modelagem dos Mapas, viabilizasse a compreensão dos conteúdos históricos aos alunos do 90 Ano proporcionando assim a construção de conhecimento por cada um, como demonstrado no mapa conceitual (figura 1).

Figura 1 - Mapa Conceitual: como poderia ser evitada a quebra da Bolsa de Nova York? 


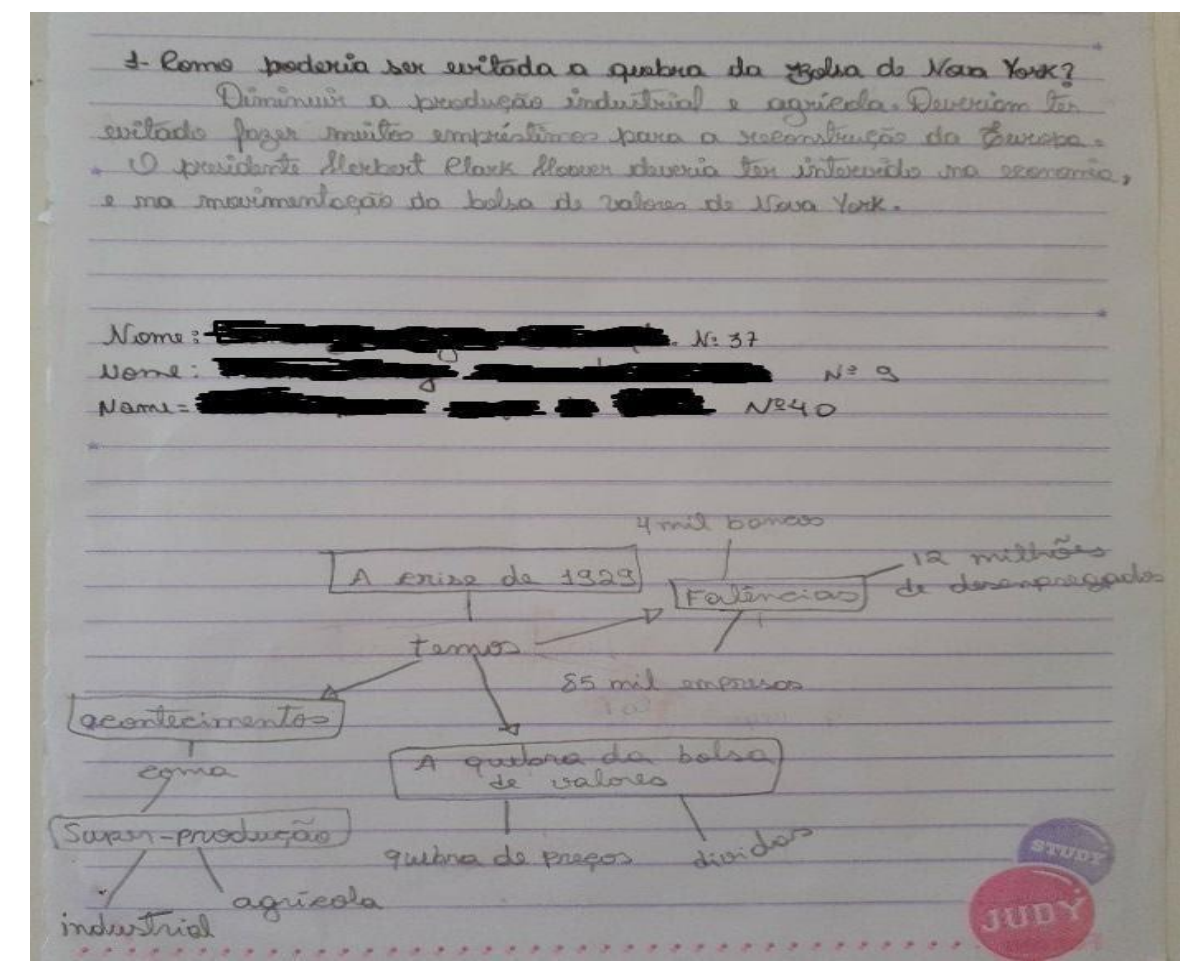

Fonte: Elaborado por alunos da Escola Estadual Professor José da Silveira Camerino.

Essa etapa do estudo serviu como ferramenta avaliativa para o professor, bem como demonstrar o conhecimento prévio de cada aprendiz sobre o conteúdo e a forma como cada conceito foi utilizado na conexão deste conhecimento. Para tanto, os alunos desenvolveram o projeto "Como poderia ser evitada a quebra da Bolsa de Nova York?", depois de terem visto o conteúdo em sala de aula, através da leitura de livro e da exibição de documentário, elencaram as possíveis soluções e em seguida produziram o mapa manualmente, sem o auxílio da ferramenta Cmap Tools, com os conhecimentos prévios que tinham.

Analisando o mapa, constatamos que a profundidade dele é pequena, devido ao uso apenas do conhecimento prévio que possuíam sobre o assunto, ou seja, há poucos conceitos e conectores para desenvolver uma melhor compreensão sobre o assunto. Para avaliar os mapas, a professora utilizou os seguintes critérios, para determinar a aquisição de conhecimento e habilidades pelos alunos:

- Utilizar, segundo Moreira (2012, p. 6-7), nos mapas, conceitos para demonstrar o conhecimento prévio pertencente a cada aluno (aprendizagem significativa); 
- Organização hierárquica dos conceitos em relação aos termos, segundo Cury, Gava e Menezes (2002);

- Determinar, segundo André et al. (1984, p. 190) a quantidade de conceitos apresentado pelo aluno;

Para tanto, o Modelo Avaliativo de Aprendizagem Cognitiva do Ensino de História (Figura 2, figura 3 e figura 4), foi criado pela pesquisadora com 0 objetivo de avaliar o desenvolvimento cognitivo do aluno através de projetos elaborados e baseados na elucidação de problemas contextualizados. Posteriormente, a pesquisadora analisa os mapas elaborados, após a finalização dos projetos, que serviu de ferramenta avaliativa dessa aprendizagem e que deviam apresentar uma determinada profundidade do uso de conceitos, de acordo com os critérios acima listados.

Figura 2 - Primeira etapa 


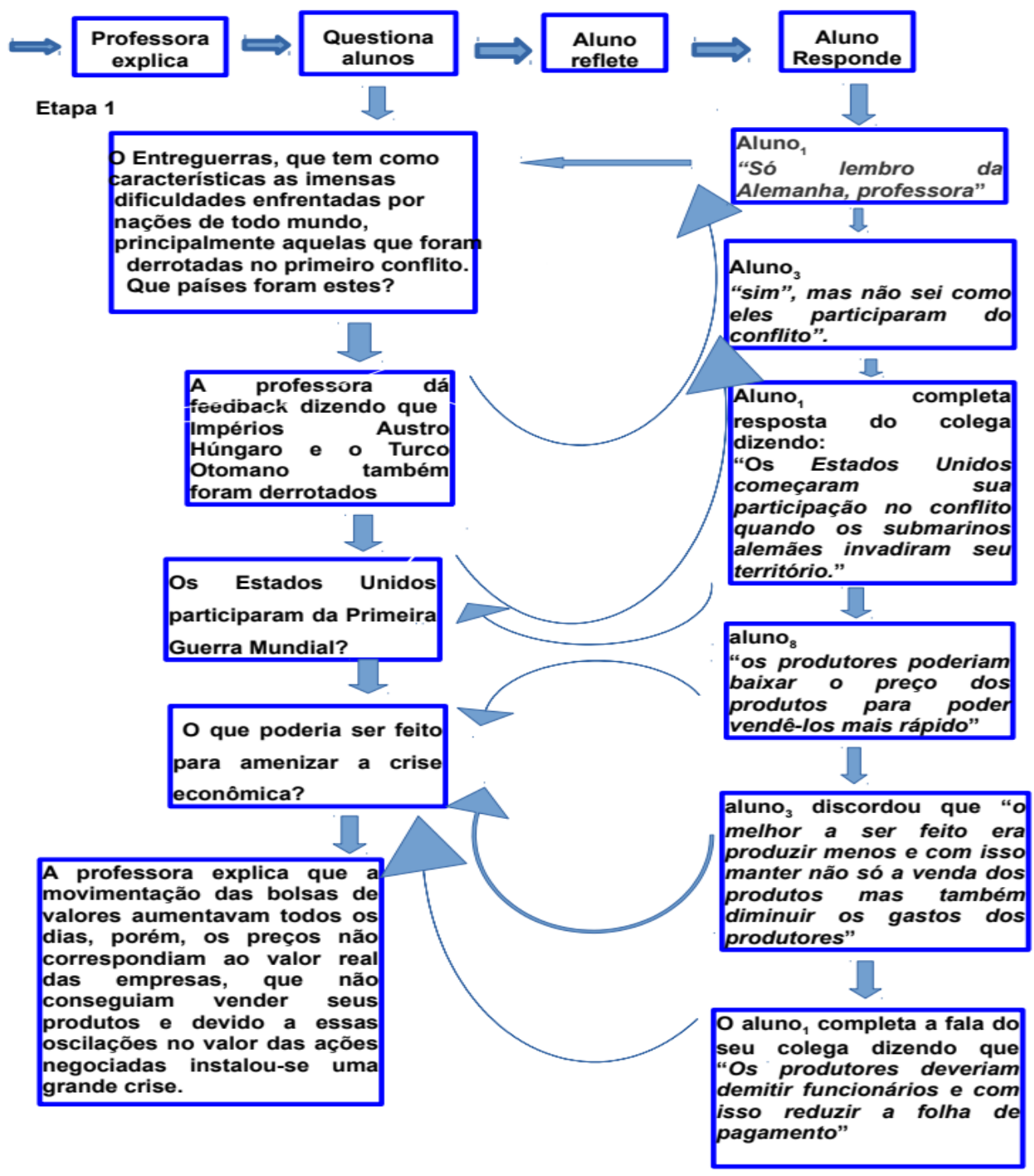

Fonte: elaborado pela autora 
Figura 3 - Segunda etapa

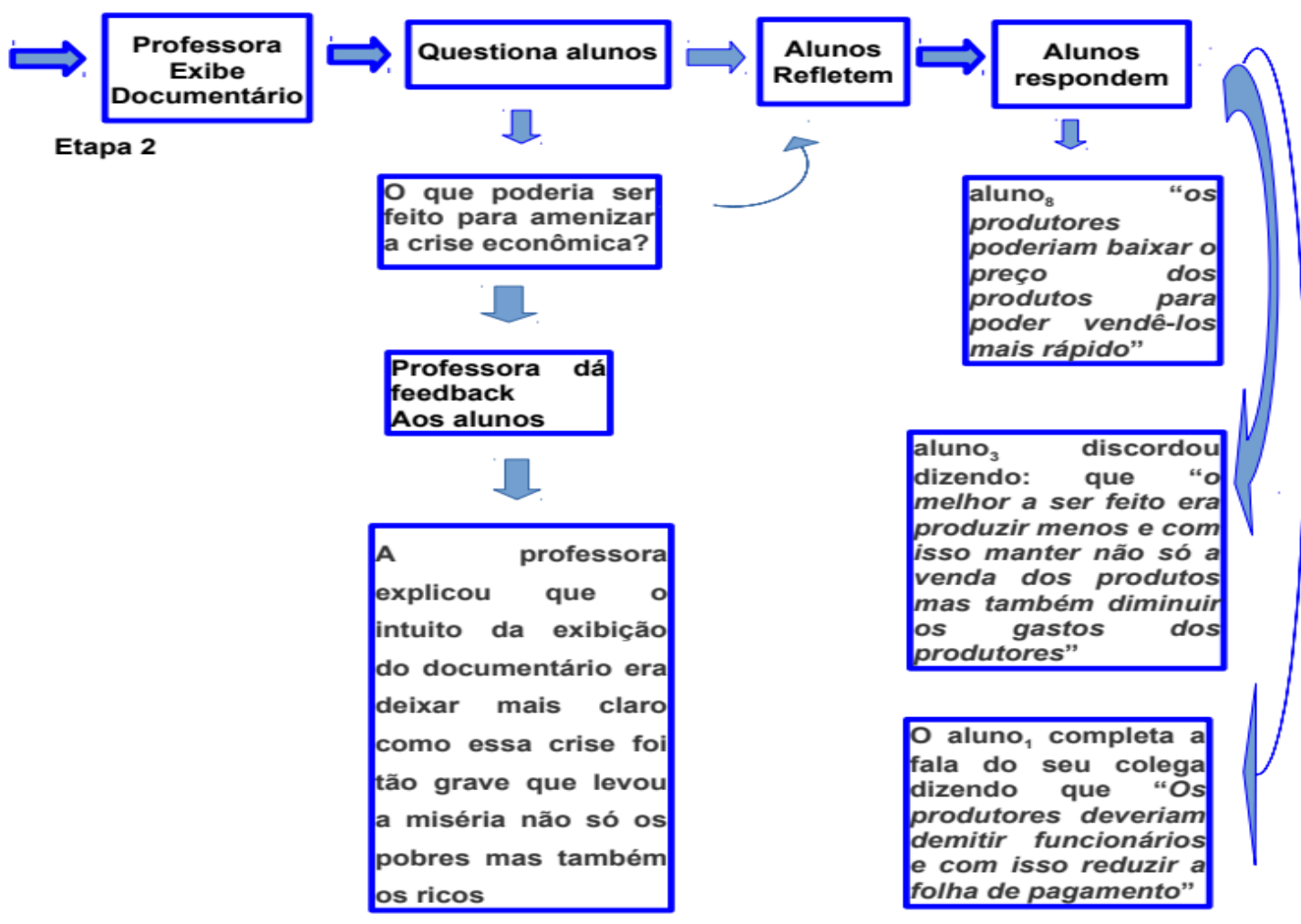

Fonte: elaborado pela autora.

Figura 4: Etapa final

História \& Ensino, Londrina, v. 27, n. 1, p. 224-240, jan./jun. 2021 


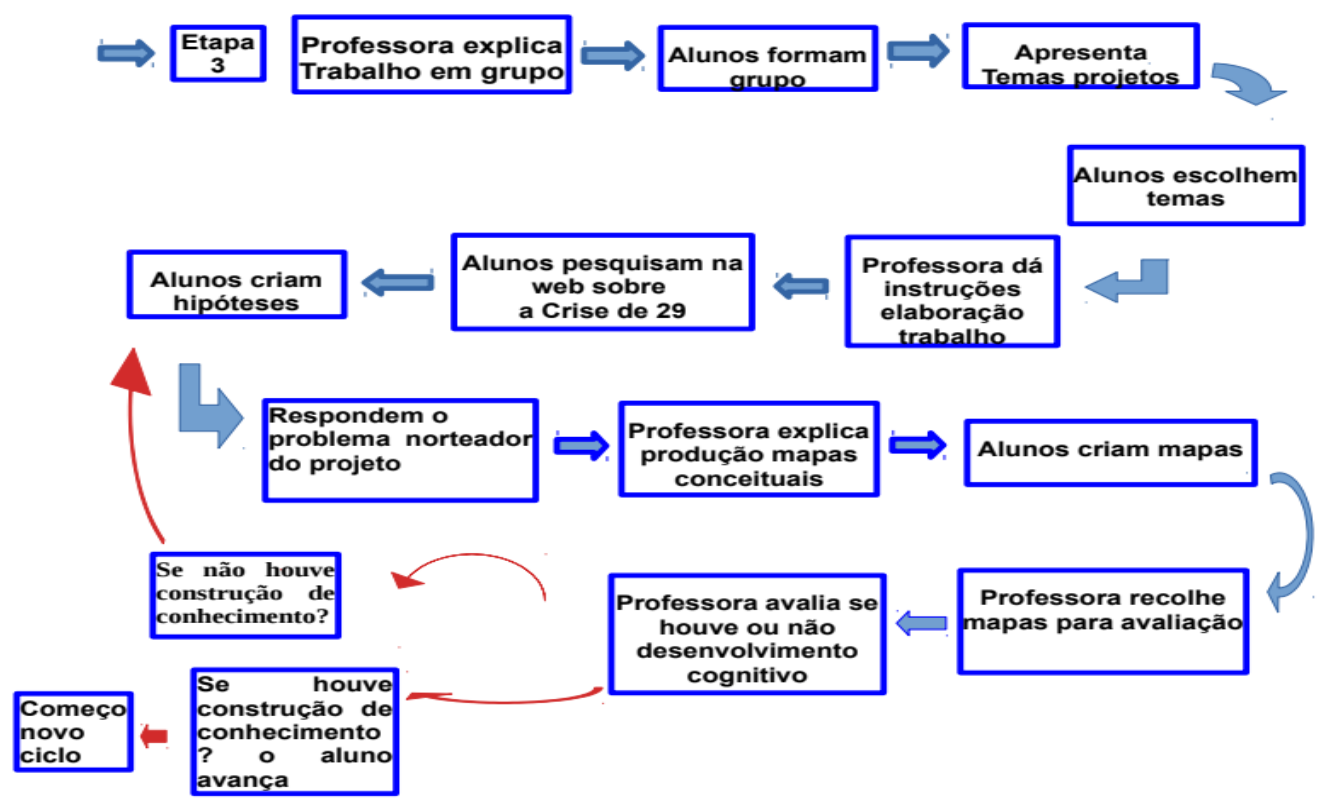

Fonte: elaborado pela autora.

Logo, o ensino de História utilizando o Modelo Avaliativo da Aprendizagem Cognitiva possibilitou ao professor desenvolver aulas produtivas em que pode questionar seus alunos sobre o conteúdo abordado, de forma a criar um momento de interação entre ele e os alunos. O modelo pode ser utilizado em várias disciplinas da área de Humanas, visto que suas etapas podem ser adequadas pelo professor ao ensino de sua disciplina.

\section{Resultados e discussão}

Para realizar a avaliação do desenvolvimento cognitivo dos alunos, analisamos os mapas observando a profundidade de cada um, ou seja, quanto mais profundo, mais conceitos ele teria, que deveria ter no mínimo cinco conceitos contextualizados ao tema. Além de também avaliar se a assimilação do aprendizado do aluno e construção do conhecimento, segundo Buchweitz e Moreira (1993), através dos mapas após a pesquisa de artigos sobre o conteúdo, de forma a desenvolver projetos e mapas conceituais mais ricos em informações, como demonstrado no mapa (figura 5). 
Figura 5 - Mapa Conceitual construído por aluno através do programa Cmap Tools

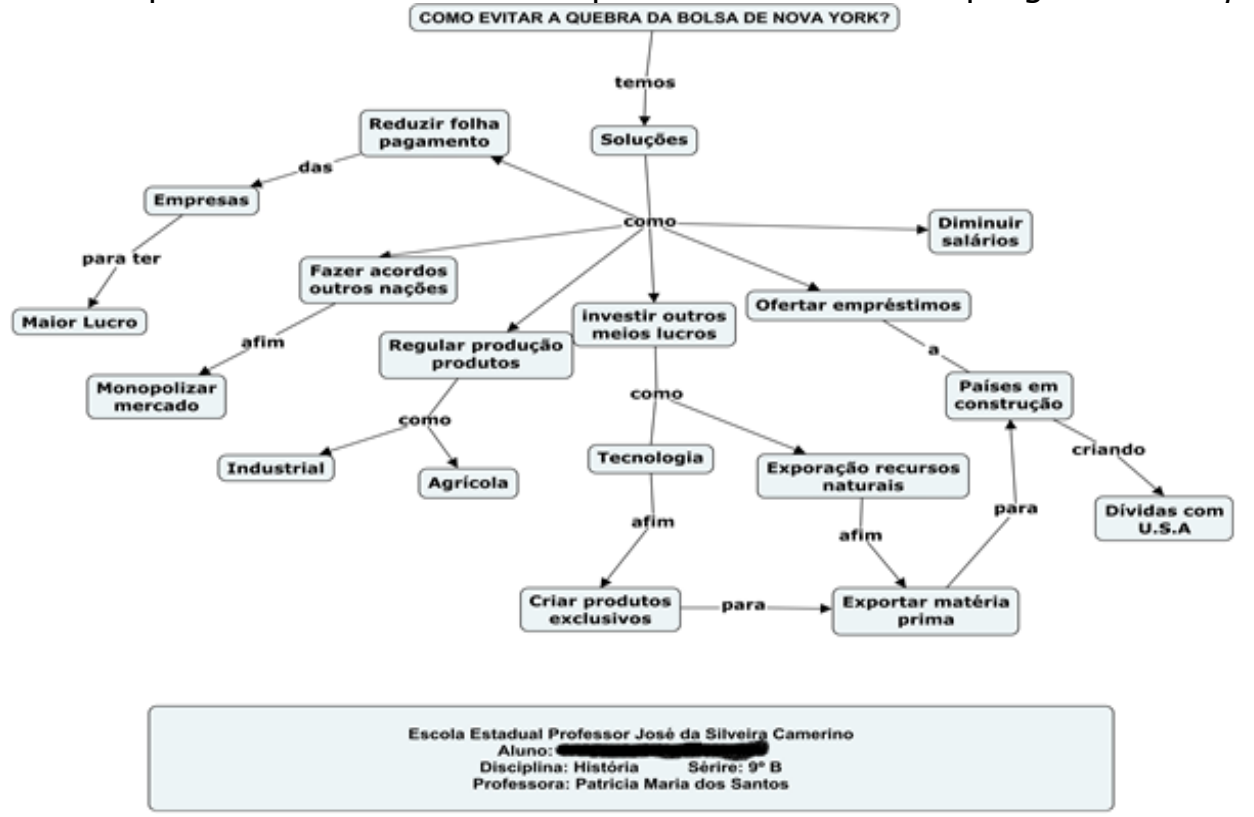

Fonte: Elaborado por um aluno da Escola Estadual

Assim contabilizamos, por exemplo, que no mapa (figura 5), foram elaboradas hipóteses para solucionar os problemas, onde o aprendiz trabalhou com os conceitos e termos de forma hierárquica e contextualizada mantendo relações entre si, explicitando que ele aprendeu novas informações. E assim, compreendemos as seguintes regras sobre as hipóteses criadas pelos alunos:

- Se diminuir à produção, então a demanda pelos produtos aumentará;

- Se os E.U.A. fizessem acordos com outras nações, na tentativa de monopolizar o mercado, então poderiam voltar a exportar mais;

- Se reduzir a folha de pagamento das empresas nos E.U.A., então elas, reduzirão gastos;

- Se investissem na tecnologia, a fim de criar produtos exclusivos, então, forçariam outros países a importar esses produtos;

- Se os E.U.A. ofertassem empréstimos aos países atingidos pela crise, então, esses países contraíram dívidas com os eles;

- Se os E.U.A. investissem em outros meios de lucro, como a exploração de recursos naturais, então teriam novas matérias primas para exportar. 
A análise das produções de mapas foi realizada através da observação dos mapas construídos pelos aprendizes durante a pesquisa. Estes dados foram detectados através da participação dos aprendizes durante as aulas teóricas e práticas, onde foram expostos conhecimentos que eles possuíam sobre o conteúdo estudado. Observamos também que eles utilizaram novos conceitos, explicitando que construíram novos conhecimentos sobre o mesmo assunto como demonstrado no mapa (figura 5).

Esses avanços foram adquiridos após as pesquisas realizadas na web, além da resolução dos problemas, evidenciando que o uso da abordagem de PBL, proporcionou uma aprendizagem e construção de conhecimento mais enriquecedor, além de proporcionar uma interação entre os aprendizes.

\section{Considerações Finais}

Esta investigação passou por várias etapas para chegar a sua efetivação. Foi proposta inicialmente, a criação do Modelo Avaliativo de Aprendizagem Cognitiva de História representando as etapas do processo de aprendizagem do aluno através da utilização da Aprendizagem Baseada em Projetos. Outra etapa realizada foi a utilização de problemas contextualizados que teve como objetivo tornar as aulas mais construtivas e provocar os aprendizes a construir seu próprio conhecimento, através de questionamentos e discussões realizadas durante a abordagem do conteúdo trabalhado.

Essa metodologia obteve sucesso, já que os aprendizes trabalharam de forma investigativa e com autonomia, orientados pelo professor e utilizando textos para a discussão da historicidade do conteúdo, e das questões criadas por eles. Observou-se que a etapa da aplicação da Aprendizagem Baseada em Projetos proporcionou momentos de discussões sobre cada problema, onde as equipes desenvolveram seus projetos em momentos de cooperação e colaboração entre os aprendizes, favorecendo o desenvolvimento da elaboração dos trabalhos finais.

A criação dos projetos foi realizada com sucesso, de forma a facilitar a construção dos mapas, já que os aprendizes realizaram mais pesquisas, de forma a aumentar o seu conhecimento, demonstrando que a abordagem de 
Aprendizagem Baseada em Projetos alcançou com êxito o objetivo de construir e demonstrar o conhecimento dos aprendizes, pela praticidade de sua utilização e pelo seu êxito em trabalhar com conceitos para a elaboração de soluções para cada problema.

Isso ficou constatado após a criação dos mapas, sobre cada problema, no programa utilizado pelos aprendizes, demonstrando que eles tinham adquirido a habilidade de representar a produção de conhecimento através dessa ferramenta, utilizando assim os conceitos que mantivessem relações complementares. Além disso, também foi proposta, a criação de mapas pelos aprendizes que refletiram a sua evolução cognitiva e a proposição de uma sequência de experimentos para analisar a sua evolução conceitual.

Começamos pela etapa da parte teórica que tratou da apresentação do projeto a ser desenvolvido na escola, onde destinamos o uso de uma abordagem construtivista para auxiliar na construção de conhecimento através do uso de técnicas de Mapas Conceituais que foi utilizada como forma de avaliar o desenvolvimento dos alunos no referido estudo, sobre problemas criados do conteúdo estudado.

A proposta inicial da criação dos mapas era que eles obtivessem o maior desenvolvimento de conceitos de acordo com o conhecimento prévio de cada aprendiz sobre o conteúdo, ou seja, eles deviam criar um mapa que apresentasse o maior número de conceitos e que estes mantivessem relação uns com os outros. Após a produção dos mapas, foram selecionados os que tiveram melhor desenvolvimento de conceitos, bem como o melhor desempenho dos aprendizes que realizaram a tarefa com autonomia.

Então, podemos concluir através dos dados, que o uso da abordagem de Aprendizagem Baseada em Projetos assim como dos Mapas Conceituais, contribui para a construção do conhecimento à medida que os aprendizes utilizam os conceitos e termos históricos de forma coerente existindo entre eles relações de complemento, além da elaboração e representação do pensamento através dos conhecimentos adquiridos anteriormente.

A implantação e introdução tanto da abordagem de Aprendizagem Baseada em Projetos como da modelagem de Mapas na aprendizagem de conceitos de História, pode ser compreendida como uma nova metodologia de 
aprendizagem e avaliação - que consiste no processo de aprendizagem através da elaboração e resolução de problemas pelo aluno sobre determinado conteúdo, que posteriormente, tem o conhecimento adquirido representado através do mapeamento de conceitos e termos sobre o assunto na forma de mapa conceitual.

Essa representação contribuiu de forma positiva para o fomento e construção do conhecimento, sendo ela também utilizada pela pesquisadora do estudo como ferramenta avaliativa no processo da aquisição desse conhecimento. A abordagem de Aprendizagem Baseada em Projetos e da modelagem de Mapas pode ser utilizada em sala de aula pelo professor como uma nova metodologia avaliativa, além de também poderem ser utilizados como um novo recurso metodológico de aprendizagem para os alunos.

\section{Referências}

ANDRÉ, Lenir C. et al. Planejamento de ensino e avaliação. Porto Alegre: SAGRA, 1984.

BUCHWEITZ, B.; MOREIRA, Marcos A. Novas estratégias de ensino e aprendizagem: os mapas conceituais e o Vê epistemológico. Lisboa: Plátano Edições Técnicas, 1993.

CARRETERO, Mario. Construir e ensinar as ciências sociais e a história. Tradução Beatriz Affonso Neves. Porto Alegre: Artes Médicas, 1997.

CAMARGO, Edson Carpes; PADILHA, Rafaela; POLACHINI, Viviane. A teoria de David Ausubel e o ensino de matemática: uma possível experiência significativa. In: CONGRESSO INTERNACIONAL DE ENSINO DE MATEMÁTICA, 6., 2013, Canoas. Anais [...]. Canoas: ULBRA, 2013. Disponível em: 116328331PB.pdf(pbworks.com). Acesso em: 27 maio 2020.

CASTANHEIRA, Ana M. P. et al. Metodologia de ensino: aprendizagem baseada em Projetos (PBL). In: COBENGE CONGRESSO BRASILEIRO DE EDUCAÇÃO ENGENHARIA, 40., 2012, Belém. Anais [...]. Belém: Abenge, 2012. Disponível em:

http://www.abenge.org.br/CobengeAnteriores/2012/artigos/104325.pdf. Acesso em: 18 out. 2016.

CURY, Davidson; GAVA; Tânia Barbosa Salles, MENEZES; Crediné Silva de. Aplicações de mapas conceituais na educação como ferramenta meta cognitiva. Vitória: Universidade Federal do Espírito Santo, 2002. Departamento de Informática. Disponível em: 
http://www.geografia.ffch.usp.br/posgraduacao/apoio/apoio_raffo/flg5052/aula_ 1/aplicacoesdeMapasConceituaisnaEducacao.pdf. Acesso em: 22 out. 2014.

GUERRA, Aida; VASCONCELOS, Clara. Aprendizagem baseada na resolução de problemas e construção de materiais didácticos na temática

"Sustentabilidade na Terra". CAPTAR, [S. I.], v. 1, n. 2, p. 147 - 165, 2009. Disponível em:http://revistas.ua.pt/index.php/captar/article/view/2718. Acesso em: 5 nov. 2016.

HINTERHOLZ, Lucas Tadeu; SANTOS, Wilk Oliveira. Aprendizagem baseada em projetos: relato de introdução da lógica no ensino fundamental. In: CONGRESSO BRASILEIRO DE INFORMÁTICA NA EDUCAÇÃO,6., 2017, Maceió. Anais [...]. Maceió: [s. n.], 2017. Disponível em: Aprendizagem Baseada em Projetos: Relato de Introdução da Lógica no Ensino Fundamental | Hinterholz | Anais do Workshop de Informática na Escola (br-ie.org). Acesso em: 27 maio 2020.

KANTOVITZ, Geane. A Disciplina de história e a formação para a cidadania: uma experiência interdisciplinar. EntreVer, Florianópolis, v. 2, n. 2, p. 95109, jan./jun. 2012. Disponível em:

http://incubadora.periodicos.ufsc.br/index.php/EntreVer/article/ViewFile/1634/2 550. Acesso em: 26 mar. 2017.

KLEIN, Ana Maria. 0 uso da aprendizagem baseada em problemas e a atuação docente. Brasilian Geographical journal: Geosciences and Humanities research medium, Ituiutuba, v. 4, p. 288-298, jul./dez. 2013. Disponível em:htpp://repositório.unesp.br/handle11449/122625. Acesso em: 16 jun. 2015.

MOREIRA, Marcos A. Mapas conceituais e aprendizagem significativa.

Revista Chilena de Educação Científica, Chile, v. 4, n.2, p. 38-44, 2012.

Disponível em: www.if.ufrgs.br/ moreira/mapasport.pdf. Acesso em: 22 out. 2014.

OLIVEIRA, Thiago L. dos Santos. Os Fundamentos da história enquanto ciência e disciplina escolar: paradigmas e orientações delineadoras. [S. l.: s. n.], 2015. Disponível em:

periodicos.pucminas.br/index.php/revistaich/article/download/11001/8826.

Acesso em: 14 fev. 2018.

RABELO, Edmar Henrique. Avaliação: novos tempos, novas práticas. 8. ed. Petrópolis: Vozes, 2009. 